DISCOVERY OF AN

\section{A NASTOMOSIS}

BETWEEN 'THE

\section{FOURTH AND FIFTH PAIR OF NERVES.}

\section{To the Editor of $\mathrm{TH}_{\mathrm{H}} \mathrm{LANCET}$.}

SIR,-I beg to make known, through the medium of your useful and extensively-circulated journal, the existence of an anastomosis between the fourth and filth pair of nerves, which I last winter discovered, whilst dissecting for Dr. Macartuey of Dublin. The communication commonly takes place by means of a slender twig, which proceeds obliquely upwards and forwards, from the first division of the fifth to the fourth parr, as these nerves are passing the cavernous sinus on their way to the orbit, and immediately before the fourth pair comes to be in contact with the first division of the fifth. Occasionally, however, the anastomosis occurs in a manner somewhat different, and this is the case in the preparation which 1 have before me. The filament, instead of taking the course above mentioned, passes in a direction obliquely from behind forwards, from the fourth pair to the first division of the fifth. The dissection in which $I$ made this discovery was very closely examined with a lens by Dr. Macartney and many others in Dublin, and from the evident plexiform arrangement of the fibres of the respective trunks with the anastomosing filament, no doubt whatever was entertained of the communication. I have since, whilst in Edinburgh, had an opportunity of showing a fresh dissection to Dr. R. C. Rudolphi of Berlin, Mr. Lizars, and other eminent anatomists, and they are all equally satisfied of the existence of the anastomosis. As there is no mention made of it in the works of Soemmering, Scarpa, Swan, or any of those who have made minute anatomy their particular study, I may infer that it has hitherto been unknown to the profession, and this I am sure you will consider a suficient excuse for requesting the insertion of this letter in a comer of The Lancer. I am, Sir, Your obedient servant,

Edinburgh, Feb. 3, 183\%.

$$
\text { S. W. FEARN. }
$$

\section{WESTMINSTER HOSPITAL.}

CLANDESTINE REMOVAL OF DEAD BODIES.

To the Editor of Tan Laveet.

Sir,-I am surprised you should be so simple as to represent, on the mere statement of your anonymous correspondent
W.M., that removing the bodies of patients who die in the Westminster Hospital, without consent of their relatives, is merely of recent date in that place. It was done there many years ago.

When $\dot{i}$ was receiving my education in surgery in another place, in the year 1782, I was familiarly acquainted with many men who belonged to the Westminster Hospital, some as professors, others as pupils; among the rest was one William Lvnn; this young man came from Newcastle-uponTyne, where be was apprenticed to an apothecary, and received the common education given to such men in those days; he then came to London, fortunately for himself, when the Westminster Iospital stood so low in public estimation, that the apothecary to that institution wanting an assistant to serve in the hospital shop, could not induce any pupil in the house, if there was one in it, to undertake the situation, and was forced to advertise the office. Lynn, who applied for, was so fortunate as to gain it, and soon after he was inducted, we became familiarly acquainted, and while we were so, Lynn told $m=$ the following story :-

The treatment of what was called Pott's disease in the spine was so imperfectly known, that every patient afficted with it died. The wise men of the west would not try Pott's plan, and all their patients died, after long sufferings, as I had numerous opportunities of knowing. One of the nurses to the hospital had a daughter aged sixteen or seventeen labouring under this disease. She was taken into the house, where everything which could be done for her, except Pott's treatment, was tried; but she also died; and, as the poor moiher knew full well what went with the bodies of other patients who died in the hospital, slıe determined that the remains of her dear child should receive christian burial, but though she believed she succeeded in her object, she was deceived, and as the subject is of some curiosity, to explain it I refer to the annexed ichnography of the ground-floor.*

The body was placed in the dead-house as usual. The mother would have locked the door, but, unfortunately, the key being lost, pro tempore at least, as a substitute she locked the door of the great-room nearest the dead-house, with a determination that no one should pass through that door till the body was buried. When the colfin was brought she went into the dead-house, saw the body properly deposited in it, the lid applied, and the man fix in the first screw. At that critical moment an outcry was raised in the ward for the nurse, one of whose patients was alarmingly ill; she

* The plan is not necessary to the description.ED. L. 
obeyed the call, but without losing her trace of feculent matter. In these two presence of mind, for she locked the room stools there were at least three pints of door and kept the key in her hand.

No time was now to be lost. Out of the window of the apothecary's room jumped the men who were secreted for the purpose, conveyed the body from the coffin to the room they had left, whence they carried something which resembled it in bulk and weight into the coffin. The undertaker bastened to screw it down, and had nearly concluded his job, when old nursey returned, and, seeing he had made such good use of his time, followed the coffin to the grave, with a full conviction that she had rendered the last duties in a becoming manner to the remains of her daughter.

William Lynn often told me this story limself, and we have frequently laughed together at the cleverness with which the trick was managed. Lynn has likewise shown me in his own possession the preparation of a very bad case of diseased spine, which he told me was taken from this patient. It he did not speak the truth, I am not to blame. I am, \&c.,

73, Upper Berkeley Street,

'T. Sheldrate.

Portman Square.

CASE OF HAMORRHAGE FROM THE BOWELS.

\section{Tothe Editor of The Lancer.}

Sin,-The following case occurred to me of late. I relate it merely from memory, and have not been particular as to the minutia of treatment, as I consider those of secondary importance. The extent of hremorrhage was very great, and I believe similar cases not firequent. $\mathbf{M r}$. $\mathbf{M}^{6} \mathbf{N}^{\prime}$ amara saw the case with me. I am, Sir, your obedient servant,

$$
\text { E. Heron, Lic. R.C.S.I. }
$$

Dublin, 18, Belvidere Place, Feb. 1832.

J. H., aged 22, of strong and actice habit, but of lymphatic appearance, had been indisposed for a few dass from cold, not accompanied with fever. On Saturday, the $2 \mathrm{~d}$ of December, he complained of slight pain in the back, with a sensation of chilliness, though he felt an unnatural sensation of heat throughout, in consequence of which he obtained a purgative powder. Early in the morning he had occasion to go to stool, and, upon examination, the evacua. tion was found to consist of blood, fluid and of venous character. In a short time the evacuation was repeated, and prosed to be of the same nature, containing a small

No. 44.5. blood discharged. In about an hour he had another evacuation of about a pint, slightly coagulated. He felt a good deal debilitated, but had no syncope. Two days previous he had slight hæmatemesis. On examination his pulse was 84 , and regular; skin not hot, with slight tendency to partial moisture; no petechiæ; gums natural; tongue moist and coated, with a dark fur, particularly at its base; urine rather dark; had no headach ; complained of slight pain a little below the umbilicus. All other parts of the abdomen bore pressure without. inconvenience. Slight tympanitis. He was ordered dilute sulphuric acid, and took about three drachms in the twenty-four hours; also acetate of lead, with opium, given at such intervals as not to be impaired by the acid. On the 4 th he had a discharge of about a pint, which was more coagulated, and did not resolve itself into its component parts ; pulse 90 ; small tend. ency to perspiration; complains of headach; countenance more sullow; restlessness. Medicine continued. An enema of six grains of acetate of lead, with forty drops of tincture of opium, which was followed by sound and refreshing. sleep. The two following days no evacuation, but medicine continued. 7th. Got, in addition, purgative medicine and puryative enema, which produced larse discharges from the bowels like brown paint, but no trace of feculent matter, the bowels having been well freed previous to this attack. Since then the evacuations have been natural.

The subject of this case had for sams time previous indulged in dissipation, but, a short time prior to the attack, had $a b=$ stained from it. Was this, therefore, the result of a cessation from the stimulus ? It is quite obvious that the disease was one of congestion, or increased action of the mucous surface of the intestinal canal generally, which is also to be inferred from the hrematemesis. I think it was not the lead, which did not exceed fifteen grains, but the acid, which checked the disense.

I think we too much neglect the application of remedies to the rectum, and often apply them to the stomach, when perhaps its energy is so impaired as to render it unimportant to produce the necessary changes in the medicine. In this case opium had been given with the lead, in nearly equal doses, without producing: tranquillity of the system, or tendency to repose; but when applied to the rectum, it produced the desired result. There could not have been less than three quarts of blood lost in this case in a very short lapse of time. 